\title{
Responsabilidad civil en materia de prácticas restrictivas a la libre competencia*
}

\author{
Civil liability in the field of restrictive practices to free competition
}

Gustavo Adolfo Beltrán Valencia ${ }^{1 \star}$

Fecha correspondencia:

Recibido: 25 de julio de 2020.

Revisión: 9 de noviembre de 2020.

Aceptado: 9 de noviembre de 2020

Forma de citar:

Beltrán, Gustavo Adolfo.

"Responsabilidad civil en materia

de prácticas restrictivas a la libre

competencia." En: Revista CES

Derecho. Vol. 11, No. 2, junio a

diciembre de 2020, 108-136.

Open access

Términos de uso

Licencia creative commons

Etica de publicaciones

Revisión por pares

Gestión por Open Journal System

DOl: http://dx.doi.org/10.21615/

cesder.11.2.7

ISSN: 2145-7719

Sobre el autor:

1. Abogado Universidad de

Medellín, Especialista en Derecho

Comercial Universidad Pontificia

Bolivariana, Magister en Derecho

Privado Universidad de Medellín,

Estudiante Doctorado en Derecho

Universidad de Buenos Aires

(Argentina), Docente de Tiempo

Completo Universidad Autónoma

Latinoamericana. Colombia.

\section{Resumen}

El derecho de la competencia comprende dos normativas, por un lado, las normas relativas a la competencia desleal, y por el otro, las normas sobre prácticas comerciales restrictivas; sin embargo, a diferencia de lo que ocurre con aquellas, las conductas anticompetitivas carecen de un régimen especial de responsabilidad civil individual, dicha situación no se compadece con un derecho de la competencia adecuado para la protección de la libre y leal competencia, máxime que con los avances tecnológicos actuales, existe la posibilidad de que los agentes comerciales lleven a cabo conductas anticompetitivas mucho más sofisticadas y complejas con una alta potencialidad de causar daños a los demás intervinientes dentro del mercado, de ahí que se proponga la estructuración de un régimen particular de responsabilidad civil derivado de los daños producidos por las prácticas anticoncurrenciales, mucho más coherente con un régimen constitucional fundamentado en la protección a la libre y leal competencia.

Palabras clave: Acuerdos Anticompetitivos, Abuso de posición dominante, Concentración empresarial, Responsabilidad civil, Prácticas restrictivas a la libre competencia.

\section{Abstract}

Competition law comprises two regulations, on one hand, the rules related to unfair competition, on the other, the rules on restrictive business practices, however, anti-competitive conduct lacks a special regime of individual civil responsibility, this situation does not comply with an adequate competition law to protect free and fair competition, especially with current technological advances, there is the possibility that commercial agents carry out much more sophisticated and complex anti-competitive practices with a high potential to cause damage to other market participants, hence the proposal of structuring a particular regime of civil liability derived from the damages caused by anti-competitive practices, that is coherent with a constitutional regime based on the protection of free and fair competition.

Key words: Cartel, Abuse of dominant position, Trust, Tort Law, Restrictive practices to free competition. 


\section{Introducción}

Nuestra Constitución Política de 1991, en su artículo 333, consagra el principio de la libertad económica, el cual debe orientar todo nuestro sistema jurídico-económico de libre mercado; dicho principio se desdobla a su vez en la libre iniciativa privada, la libertad de empresa, y la libre y leal competencia.

La libre iniciativa privada y la libertad económica, hacen referencia a la posibilidad que tienen los asociados de iniciar la actividad económica que a bien tengan, siempre y cuando esta se encuentre dentro de los márgenes de la legalidad y la licitud, y no contraríen normas imperativas o al orden público económico.

Por su parte, la libre y leal competencia, tiene que ver con que al iniciar una actividad económica no se restringa injustificadamente, y se garantice la posibilidad de poder ingresar al mercado a competir con los demás empresarios en la búsqueda de la clientela en situación de igualdad y transparencia, por lo que adicionalmente dicha competencia se debe de realizar de buena fe y con lealtad.

Refiriéndose a la libertad económica manifiesta Velilla (2013):

La liberta económica tiene un doble contenido: en primer lugar, la libertad de empresa, o fundamento de la actividad particular y de los derechos inherentes a ella, que pueden hacerse valer frente a la intervención del Estado cuando este pretenda reglamentarla; y en segundo lugar, la libertad de competencia, o sea, el derecho a competir con otro sin ser discriminado, lo que naturalmente conduce a limitar las condiciones en las cuales las personas públicas pueden participar en la actividad económica sin desnaturalizar la competencia. (p. 119).

Ahora bien, dadas estás garantías de orden constitucional y los múltiples beneficios que la competencia genera dentro de un mercado ${ }^{1}$, es que el sistema jurídico proscribe todas aquellas prácticas y actos, que de manera artificiosa limitan o inhiben la competencia dentro del mismo, y todas aquellas conductas que atentan contra las sanas costumbres mercantiles, los usos honestos y la buena fe mercantil que deben de ser observadas por todos aquellos que participan dentro del mercado.

La OCDE en la ficha informativa sobre los efectos macroeconómicos de la política de competencia del 2014, advierte que:

Resulta claro que los sectores con mayor competencia experimentan crecimientos de la productividad, una tesis confirmada por numerosos estudios empíricos en diferentes sectores y empresas. (...) Parece que esto se explica principalmente por qué la competencia conlleva una mejora en la eficiencia de asignación al permitir que las empresas más eficientes entren en el mercado y ganen cuota, a expensas de las menos eficientes (el llamado efecto entre empresas). Por ende, la regulación o los comportamientos contrarios a la libre competencia y a la expansión pueden ser particularmente perjudiciales para el crecimiento económico.

1. Dentro de los beneficios que la competencia apareja podemos señalar: la posibilidad de elección que tiene el consumidor, la variedad de precios y condiciones de venta y posventa, el aumento de la calidad de los bienes y servicios, así como el incentivo a la innovación y el desarrollo, etc. 
Es en este sentido, que el derecho de la competencia a estructurado todo un régimen de protección prohibitivo de las prácticas restrictivas a la libre competencia y de las prácticas constitutivas de competencia desleal.

Frente al derecho de la competencia, Castro (2016) afirma que:

El derecho de la competencia se ha convertido en una verdadera disciplina autónoma en el moderno derecho económico (...). Este ordenamiento congrega un conjunto de normas enderezadas a garantizar el funcionamiento transparente del mercado, involucrando principalmente los siguientes capítulos, diferenciables pero complementarios entre sí: normas de competencia desleal (ley 256 de 1996) (...). Derecho antimonopolístico, para el control de las prácticas restrictivas de la competencia (ley 155 de 1959, decr. 2153 de 1992 y ley 1340 de 2009, con sus normas reglamentarias). (p. 308).

En este orden de ideas, por competencia desleal en los términos del inciso segundo del artículo 7 de la Ley 256 de 1996, se entiende que:

...Se considera que constituye competencia desleal, todo acto o hecho que se realice en el mercado con fines concurrenciales, cuando resulte contrario a las sanas costumbres mercantiles, al principio de la buena fe comercial, a los usos honestos en materia industrial o comercial, o bien cuando este encaminado a afectar o afecte la libertad de decisión del comprador o consumidor, o el funcionamiento concurrencial del mercado.

Y por su lado, frente a lo que se entiende por prácticas restrictivas a la libre competencia, Rubio (2007) manifiesta que:

Básicamente es todo comportamiento que tenga la capacidad o el efecto de inhibir o disminuir artificialmente las fuentes de competencia en un mercado y de eliminar sus beneficios. (...) las normas de prácticas comerciales restrictivas buscan garantizar libertad de acceso, eficiencia en el aparato productivo, variedad de precios y calidades y libre escogencia del consumidor. (p. 31).

En este contexto podemos afirmar entonces, que tanto el régimen de competencia desleal, como el de prácticas restrictivas a la libre competencia, cumplen una función complementaria en aras del efectivo desarrollo de los principios constitucionales de libertad económica, libertad de empresa, y libre y leal competencia; en beneficio, no solamente del funcionamiento competitivo del mercado, sino también del consumidor y su posibilidad real de elección de bienes y servicios dentro del mismo.

Al respecto, afirma la Corte Constitucional en sentencia C-616 de 2001, que:

La libre competencia económica es un derecho individual y también colectivo (artículo 88 de la Constitución), que tiene por objeto el logro de un estado de competencia real, libre y no falseada, que permita la obtención del lucro individual para el empresario, a la vez que genera beneficios para el consumidor con bienes y servicios de mejor calidad, con mayores garantías y a un precio real y justo. 
Con todo, es de anotar que tanto en materia de competencia desleal, como de prácticas restrictivas a la libre competencia, se le pueden generar perjuicios a terceros participantes dentro del mercado; sin embargo, a diferencia de lo que ocurre en materia de competencia desleal- en la cual la Ley 256 de 1996 consagra un régimen especial de responsabilidad- en materia de prácticas restrictivas a la libre competencia, esto no ocurre, por lo que en el evento de causarse un daño a un tercero con ocasión del despliegue de estas conductas, este tercero tendrá que acudir al régimen general de responsabilidad consagrado en el Código Civil con el fin de lograr el resarcimiento de sus perjuicios.

Lo anterior, no se compadece con el grado de especialización y complejidad que las prácticas anticompetitivas presentan hoy en día, por lo que al igual a como ocurre tratándose de competencia desleal, los terceros afectados, deben de gozar de un régimen especial de responsabilidad civil en materia de daños que sufran por aquellas conductas.

De estas circunstancias nace el hecho que este escrito abordará la posibilidad de plantear las características más descollantes que un régimen de responsabilidad especial en materia de prácticas restrictivas debe tener, circunscribiendo en todo caso su análisis a tres de sus manifestaciones, esto es la cartelización, el abuso de la posición dominante en el mercado, y el trust².

\section{El Cártel}

Consiste el cártel en un acuerdo, convenio o concertación entre empresas independientes, y por regla general, competidoras entre sí, por medio del cual se tiene por objeto, o como efecto, limitar la libre competencia dentro del mercado.

Este tipo de acuerdos se pueden llegar a presentar en forma de contratos o acuerdos expresos, o también mediante conductas conscientemente paralelas entre las empresas involucradas en la práctica anticompetitiva. Numeral 1 artículo 45 del Decreto 2153 de 1992.

Así mismo, este tipo de acuerdos restrictivos pueden tener operancia, no solo entre empresas competidoras entre sí, por pertenecer a la misma etapa en la cadena de producción y/o distribución (acuerdos horizontales), sino que también, pueden ocurrir entre empresas pertenecientes a distintas etapas en la cadena de producción y suministro de bienes (acuerdos verticales).

Refiriéndose a esta figura manifiestan Berdugo y Palacio (2011):

Son acuerdos que, aunque no sean auténticos contratos, implican una cooperación práctica entre quienes lo celebran, a fin de evadir los riesgos normales de la competencia y de quedar en condiciones de competitividad más favorables que las normales en el mercado de bienes y de servicios. (...). Como práctica empresarial, atenta contra la libertad de competencia, en cuanto busca la reducción de la producción o la distribución de bienes, mediante la demarcación de territorios, la fijación de precios, estableciendo políticas frente a los proveedores. (p. 87).

2. Dentro de las diversas prácticas que se consideran como anticompetitivas, tenemos los acuerdos y actos restrictivos a la libre competencia, el abuso de posición dominante, el trust, el dumping y los actos de retención de facturas. Ley 155 de 1959. Decreto 2153 de 1992. Ley 1340 de 2009 . Decreto 1750 de 2015 y parágrafo 1 del artículo 778 del Código de Comercio, adicionado por la Ley 1676 de 2013. 
Ahora bien, el cártel como práctica anticompetitiva, puede asumir diversas modalidades, articulo 47 Decreto 2153 de 1992, tales como:

- De fijación directa o indirecta de precios

- Que discriminan las condiciones de venta o comercialización de los bienes frente a terceros.

- Cárteles que tienen por objeto o como efecto la repartición de mercados entre productores o distribuidores.

- Los que tienen por objeto o como efecto la asignación de cuotas de producción o de suministro.

- Los que persiguen la asignación, repartición o limitación de fuentes de abastecimiento de insumos productivos.

- Cárteles de limitación de desarrollos tecnológicos.

- Cárteles de ventas atadas o subordinadas.

- Acuerdos que tienen por objeto o como efecto abstenerse de producir un bien o servicio o afectar sus niveles de producción

- Cárteles colusorios en materia de licitaciones o concursos

- Cárteles para impedir el acceso a los mercados o a los canales de distribución por parte de terceros.

Con todo, para establecer la configuración de cualquiera de estos acuerdos anticompetitivos, basta con que la conducta tenga la potencialidad de causar una restricción a la competencia, aunque efectivamente no la realice; y adicionalmente, es indiferente el aspecto subjetivo de las empresas involucradas, en otras palabras, basta con que la conducta tenga como efecto la restricción de la competencia en el mercado, independientemente de la intención dolosa o culposa de sus participantes.

En este sentido se pronuncia Jiménez (2019):

En este sentido, para que se incurra en el ilícito concurrencial, basta con que se realice la concertación y que esta pueda llegar a afectar el sistema competitivo, incluso en aquellos casos en los cuales no se ha producido aún el efecto restrictivo de la competencia.

Igualmente, se configura el ilícito concurrencial con independencia de la intención o motivación de los implicados. Es decir, se prohíben las restricciones a la competencia en el mercado de carácter objetivo, en la medida en que se afecte o pueda afectar el nivel competitivo existente en el mercado. (p. 24).

En estos mismos términos se pronuncia la Superintendencia de Industria y Comercio, autoridad designada en Colombia para conocer en funciones administrativas de las prácticas restrictivas a la libre competencia según la Ley 1340 de 2009, cuando afirma en su guía sobre preguntas frecuentes frente al régimen de protección de la competencia que:

La normatividad vigente considera que un acuerdo puede ser anticompetitivo por su objeto o por su efecto. Son anticompetitivos por su objeto aquellos acuerdos cuyo fin, sin importar que hayan sido efectivamente ejecutados o no en el mercado, los califica como tal. Un acuerdo es anticompetitivo por su efecto cuando el resultado del mismo, sin importar el fin de las partes, tiene efectos anticompetitivos en el mercado. 
Ahora bien, con el actual auge de las nuevas tecnologías y las nuevas formas de interacción en el tráfico mercantil, dichos acuerdos anticompetitivos se pueden llevar a cabo a través de formas mucho más sofisticadas; así, por ejemplo, cobra especial relevancia el tema de los facilitadores de carteles, que como su nombre lo indica, se trata de empresas que, sin pertenecer al acuerdo anticompetitivo, colaboran con su infraestructura y gestión en la organización del mismo.

Al respecto Calderón (2019) manifiesta que:

Los facilitadores de cárteles han cobrado creciente importancia en el derecho de la competencia a nivel internacional. La persecución de las empresas o personas que sin ser pare directamente interesada de un esquema colusorio horizontal, colaboran en la organización, gestión o monitoreo de un cártel y sus reglas, ha empezado a discutirse con mayor fuerza en los últimos años, a raíz de la proliferación de este tipo de arreglos comerciales. (p. 32).

De tal suerte, que estos facilitadores del cártel ponen a disposición del mismo toda su logística, sus bases de datos, el manejo de información, sus conocimientos empresariales, etc., para que el acuerdo anticompetitivo se pueda llevar a cabo de la forma más imperceptible posible para las autoridades de la competencia; dificultando sobremanera su detección, investigación y sanción.

La legislación colombiana expresamente consagra la figura del facilitador en el artículo 2.2.2.29.1.2 del Decreto 1523 de 2015, el cual define a facilitador como: "3 Facilitador: Cualquier persona que colabore, facilite, autorice o tolere conductas constitutivas de prácticas comerciales restrictivas, en los términos establecidos en el artículo 2 de la Ley 1340 de 2009, y las normas que lo complementen o modifiquen."

Por su parte el numeral 16 del artículo 4 de la Ley 1340 de 2009, faculta a la Superintendencia de Industria y Comercio, para imponer multas a dichos colaboradores, al respecto dice este articulo:

Artículo 4: Funciones del Superintendente de Industria y Comercio.

Al Superintendente de Industria y Comercio, como jefe del organismo, le corresponde el ejercicio de las siguientes funciones:

(...)

16. Imponer a cualquier persona que colabore, facilite, autorice, ejecute o tolere conductas violatorias de las normas sobre protección de la competencia a que se refiere la Ley 155 de 1959, el Decreto 2153 de 1922 y normas que la complementen o modifiquen, multas hasta por el equivalente de dos mil (2000) salarios mínimos mensuales legales (...).

Dentro de las diversas instituciones que pueden actuar como colaboradores en la configuración y mantenimiento de un cártel, pueden estar oficinas consultoras jurídicas, suministradores de servicios, funcionarios públicos, órganos de administración de sociedades, asociaciones gremiales y profesionales, etc.

La Superintendencia de Industria y Comercio en Resolución 26129 del 25 de mayo del 2015, afirma que:

...es claro para esta Delegatura que son responsables (...) todos aquellos sujetos de derecho que hayan colaborado, facilitado, autorizado, ejecutado o to- 
lerado las conductas anticompetitivas, con independencia de si se trata o no de aquellos que son descritos como administradores en el artículo 22 de la Ley 222 de 1995, o si se trata de funcionarios o exfuncionarios, o empleados o exempleados, o si su vinculación con el agente del mercado obedece a otro tipo de relación jurídica o comercial.

Con relación a las asociaciones gremiales y profesionales como facilitadores de acuerdos anticompetitivos, Tobar (2016) aduce que:

Por ello, los empresarios deben ser muy cuidadosos en las reuniones y discusiones que se suscitan en el seno de tales asociaciones o gremios, pues en dichas reuniones se ofrecen oportunidades para que competidores directos se encuentren repetidamente, lo que puede llegar a facilitar actividades ilegales o anticompetitivas, favoreciendo la colusión. (...).

Las asociaciones deben evitar constituirse en modos de intercambio de información que permitan y faciliten la coordinación o la colusión entre sus miembros o que pongan en desventaja a miembros del mismo mercado no agremiados o agremiados que puedan verse afectados con tal investigación. (p. 357).

Y en similares términos Cortázar (2011) manifiesta que:

En la historia de los acuerdos de cartel colombianos varios gremios ocupan un papel protagónico, según lo atestigua los casos por ejemplo de la Lonja de Bogotá, Andevip, Asoleche, Asocaña, etcétera, razón por la cual últimamente la SIC ha venido pronunciándose al respecto indicando que si bien la labor gremial merece todo su respeto y apoyo de todas formas las gremios deben tener en cuenta que existen límites y que ciertas actividades deben ser conducidas con especial cuidado para evitar el riesgo de incurrir en conductas anticompetitivas." (p. 77).

Y la Superintendencia de Industria y Comercio señala en la cartilla sobre la aplicación de las normas de competencia, frente a las asociaciones de empresas y asociaciones o colegios de profesionales, que:

Las asociaciones de empresas o gremios y las asociaciones de profesionales están obligadas a desarrollar sus actividades dentro del marco del régimen de protección de la competencia el cual prohíbe, entre otros, los acuerdos y actos contrarios a la libre competencia. Por lo tanto, una vez integrada la asociación por un numero plural de sujetos, la misma adquiere los mismos deberes que cualquier otro particular en relación al régimen legal de protección de la competencia. (pagina 6 cartilla sobre aplicación de las normas de competencia frente a las asociaciones de empresas y asociaciones o colegios de profesionales.

En este orden de ideas, los facilitadores de la cartelización se convierten en instrumentos eficaces para el intercambio de información estratégica entre las empresas involucradas en las prácticas anticompetitivas, disminuyendo los riesgos de su detección por parte de las autoridades de control de dichas conductas, lo que se agrava aún más con los nuevos avances tecnológicos, de softwares, inteligencia artificial y algoritmos, etc., que invisibilizan aún más su estructuración y mantenimiento. 
De ahí que para hacerle frente a los retos que plantean todo este tipo de conductas y sus eventuales daños, se deba de estructurar todo un régimen de responsabilidad especial, más acorde con dichas situaciones, y que no se encuentre, como sucede actualmente, atado al régimen de responsabilidad decimonónico de la legislación civil.

\section{Abuso de Posición Dominante}

De conformidad con el numeral 5 del artículo 45 del Decreto 2153 de 1992, por posición dominante se entiende: "La posibilidad de determinar, directa o indirectamente, las condiciones de un mercado".

De tal suerte que podemos entender que una empresa posee posición dominante en un mercado cuando puede actuar e imponer las condiciones de negociación dentro del mismo, con independencia de la reacción de los demás competidores, proveedores, distribuidores, consumidores y clientes.

"Resumiendo, se puede decir que el elemento fundamental que estructura la posición dominante consiste en la potestad de realizar negocios jurídicos con independencia real frente a sus competidores y a sus clientes en los negocios específicos que se realicen". (Pineda, 2013, p. 93)

La posición de dominio de una empresa se mira con relación a un determinado mercado; es decir, a un mercado relevante, para lo cual se debe de tener en cuenta un elemento territorial y un elemento objetivo o del producto, de manera que entre más amplio territorialmente hablando sea un mercado, más competidores habrán y más reducidas serán las posibilidades que exista posición dominante dentro del mismo; y por otro lado, el elemento objetivo tiene que ver con el grado de fungibilidad que tiene el producto que se ofrece, pues si existen empresas que pueden producir bienes sustitutos del mismo, se reduce la posibilidad de ostentar posición de dominio dentro del mercado.

En este sentido afirma Rengifo (2004):

...para saber si una empresa se encuentra en una posición dominante es presupuesto necesario la determinación del mercado en donde se ejerce esa posición. La doctrina ha elaborado tres criterios para la delimitación del mercado relevante: criterio geográfico, criterio temporal y criterio objetivo. De acuerdo con el primero y el segundo se debe delimitar espacial y temporalmente el mercado, es decir, en qué lugar se ejerce la posición de dominio y en qué o durante cuánto tiempo; (...). El criterio objetivo hace relación al producto o servicio que se ofrece en el mercado; pero la delimitación objetiva no mira tanto a la identidad física o técnica de los productos o servicios, sino su igualdad económica, es decir, que en el evento de faltar uno, el consumidor lo pueda sustituir por otro en la medida en que ambos satisfacen la misma necesidad. (p. 412 y 413$)$.

Con todo, tener posición de dominio dentro de un mercado, no es ilegal, pues un empresario pudo llegar a gozar de esta en virtud de conductas irreprochables, como la calidad de sus productos, sus precios, las condiciones favorables de venta y posventa, campañas de publicidad agresivas, niveles elevados de tecnología e innovación etc.; por el contrario, lo que el sistema jurídico proscribe es el abuso que se realice de esta posición dominante. 
En estos términos, se pronuncia la Superintendencia de Industria y Comercio en la Resolución 3694 del 5 de febrero de 2013:

En este punto cabe aclarar que el hecho de tener una ventaja competitiva en el mercado que sirva para aumentar la participación, detener o retrasar su perdida, no es en sí mismo reprochable por el derecho de la competencia, sino que será necesario que dicha ventaja haya sido adquirida de forma injustificada y artificial, de tal forma que no se explique por consideraciones de eficiencia de la empresa, sino por determinaciones que no tienen explicación económica suficiente. (resolución 3694 del 5 de febrero de 2013 SIC.

En idéntico sentido, se pronuncia la Jurisprudencia de la Corte Constitucional en la sentencia T-375 de 1997:

Las normas sobre competencia se enderezan a evitar concentraciones en los mercados $\mathrm{y}$, desde este punto de vista, pueden proponerse evitar que se den posiciones dominantes. Sin embargo, cuando estas se presentan o cuando la ley las tolera, lo que puede obedecer a razones de eficiencia, lo que en modo alguno se puede permitir es que, además de este factor de pérdida de competitividad, las personas o empresas en esa situación hagan un uso abusivo de su posición dominante o restrinjan y debiliten aún más el nivel de competencia existente.

Cabe anotar que la Constitución Política de 1991, en su inciso 4 del artículo 333, consagra la posibilidad de intervención del estado para impedir el abuso que personas o empresas puedan realizar de su posición dominante en el mercado.

Frente a este intervencionismo estatal, manifiesta la Corte Constitucional en sentencia C-815 de 2001:

La protección a la libre competencia económica tiene también como objeto, la competencia en si misma considerada, es decir, más allá de salvaguardar la relación o tensión entre competidores, debe impulsara o promover la existencia de una pluralidad de oferentes que hagan efectivo el derecho a la libre elección de los consumidores, le permita al Estado evitar la conformación de monopolios, las prácticas restrictivas de la competencia o eventuales abusos de posiciones dominantes que produzcan distorsiones en el sistema económico competitivo.

En este orden de ideas, el artículo 50 del Decreto 2153 de 1992, establece una serie de conductas que se consideran abusivas de la posición dominante, entre las cuales tenemos:

- La disminución de precios por debajo de los costos con el objeto de eliminar a los competidores o prevenir su ingreso al mercado

- La aplicación de condiciones discriminatorias para operaciones equivalentes

- Ventas atadas

- Vender o prestar servicios en alguna parte del territorio colombiano a un precio diferente a aquel que se ofrece en otra parte del territorio colombiano, cuando el precio no corresponde a la estructura de costos de la transacción, con la intención o el efecto de disminuir o eliminar la competencia. 
- Obstruir o impedir a terceros, el acceso a los mercados o a los canales de comercialización.

Al igual a lo que ocurre tratándose de acuerdos contrarios a la libre competencia, para que se configure el abuso y sea sancionado administrativamente el agente económico que ostenta posición de dominio, no se requiere que este haya actuado con dolo o con culpa.

En palabras de Jiménez (2019):

Otro importante criterio que se ha utilizado en la aplicación de la doctrina del abuso de la posición de dominio hace referencia a la objetividad del comportamiento. Este criterio para la configuración de la conducta como abusiva, indica que no se requiere contar con la intencionalidad del autor, basta con que el comportamiento resulte objetivamente abusivo, a la luz de los criterios que hemos mencionado, sin que las autoridades de competencia deban necesariamente probar la intencionalidad para perjudicar a terceros, a los consumidores o al sistema de competencia. (p. 52)

Ahora bien, con los avances tecnológicos y las nuevas modalidades existentes para el desarrollo de las operaciones mercantiles, es que las empresas que ostentan posición de dominio en los mercados, pueden verse tentadas a abusar de ésta, a través del uso de diversos instrumentos cada vez más complejos y refinados.

En relación con esto Cóbar (2019) indica:

Los mercados digitales, representan grandes oportunidades de mejorar la calidad de vida de las personas, generando una mayor gama de productos y servicios, creación de alternativas novedosas, y un sinnúmero de oportunidades. No obstante, ello, también representa un verdadero desafío para las políticas y autoridades de competencia, pues la forma en que se producen las prácticas restrictivas de la competencia es mucho más sofisticada que antes. (p. 85)

De acuerdo a lo anterior, los agentes económicos con posición de dominio pueden hacer uso de las nuevas tecnologías, y a través del uso del Big Data, adquirir y recopilar información sobre, por ejemplo, las preferencias de los consumidores, creando un perfil de los mismos, y así poder captar su atención sobre los productos de su interés, y consecuentemente, acudir al uso de precios predatorios para limitar o eliminar su competencia en estos nichos de mercado.

En este mismo orden, los agentes económicos que hayan adquirido posición de dominio en un mercado, por el desarrollo de softwares que hayan comprobado ser un éxito en cuanto a su eficiencia y beneficios técnicos para el mercado relevante -convirtiéndose en un bien de difícil reemplazo dentro del mismo-, pueden ser usados por dichas empresas dominantes como un mecanismo de discriminación contractual de consumidores, compradores y proveedores, obstruyendo el acceso al mercado o disminuyendo y eliminando la competencia.

El éxito de un software, sobre todo si éste es un sistema operativo, puede ser tal que se convierta en un estándar para el mercado, ora porque su eficiencia técnica es inigualable, ora porque la capacitación de usuarios en productos sustitutos es económicamente ineficiente. El problema de la estandarización 
del software consiste en que la firma innovadora estará en posición de controlar para su beneficio una barrera de entrada para nuevos oferentes. (Pacheco, 2020, p. 51 y 52).

Otras situaciones de abuso de posición de dominio en los mercados, que se pueden presentar en el ámbito de los nuevos desarrollos tecnológicos, tiene que ver con el uso del denominado troll de patentes, en virtud del cual el agente de mercado con poder monopólico, se dedica a adquirir o a desarrollar patentes, no con la intención de explotarlas, sino de amenazar con demandar en forma abusiva a sus competidores como posibles infractores de las mismas, intimidándolos para conseguir acuerdos económicos extrajudiciales.

Según León y Varela (2010): “Esta figura trol de patentes es utilizada para describir a las empresas que demandan a uno o más infractores de forma oportunista y, a menudo, sin la intención de fabricar o comercializar la invención patentada." (p. 365).

De igual forma Rengifo (2004) plantea como hipótesis de abuso de posición dominante vinculada al uso de la propiedad intelectual a las siguientes:

Las cláusulas conforme a las cuales la empresa vendedora de tecnología o concedente del uso de una marca se reserve el derecho de fijar los precios de venta o reventa de los productos que se elaboren con base en la tecnología respectiva; las cláusulas que obliguen al comprador de la tecnología a transferir al proveedor los inventos o mejoras que se obtengan en virtud del uso de dicha tecnología; las cláusulas que obliguen a pagar regalías a los titulares de patentes o de las marcas por patentes o marcas no utilizadas o vencidas. (p. 439 y 440).

También como modalidad sofisticada de abuso de posición dominante en el mercado, tenemos a la denominada innovación depredadora, en donde, es más la afectación negativa al sistema concurrencial del mercado, que los beneficios que concede al sistema competitivo dicha innovación efectuada:

Definida como la alteración de uno o varios de los elementos técnicos de un producto con el objetivo de limitar o eliminar la competencia (Thiabault Shrepel, 2017), la innovación depredadora es una de esas situaciones que, aunque difícil de detectar, afecta cada vez más las dinámicas de la libre competencia. (Ibarra, 2019, p. 178).

Finalmente, es de advertir entonces que, todas estas nuevas modalidades de abuso a través del uso de nuevas tecnologías y de propiedad intelectual, que se pueden presentar por los empresarios que ostentan posición dominante, pueden afectar no únicamente un mercado especifico, sino toda una serie de mercados que se entrelazan dentro del ámbito tecnológico, lo que consecuencialmente puede acarrear una potencialidad de daño muchos más amplia a diversos participantes dentro de múltiples mercados. De ahí la importancia de plantear un régimen de responsabilidad especial en materia de daños ocasionados por prácticas restrictivas a la libre competencia.

En este sentido, Alfonso Miranda Londoño plantea en columna del periódico El Tiempo del 10 de junio de 2019, que: 
Adicionalmente, en los mercados de TICs, se ha vuelto común encontrar que más que un mercado, existe un ecosistema, en el que diferentes mercados se entrelazan y es difícil afectar un mercado (subir el precio hipotéticamente), sin afectar a otro, lo que puede llevar a conclusiones erradas y en consecuencia, lo que debemos preguntarnos es si más que definir un mercado, debería definirse el ecosistema.

\section{El Trust}

El trust consiste en la concentración de empresas bajo cualquiera de sus modalidades, y que, como consecuencia de esta, conlleva a una limitación o eliminación indebida de la competencia dentro de un mercado especifico.

El trust, en cuanto sea aprovechado para dominar el mercado o para consolidar el control de industrias en forma monopolística o en general para distorsionar la competencia, es violatorio del principio de la libre competencia económica, consagrado en el artículo 333 de nuestra Constitución y que, además, esta protegido por la ley que sanciona las conductas restrictivas de la competencia. (Berdugo y Palacio, 2011, p. 84).

Ahora bien, la concentración de empresas no es una conducta prohibida per se, solamente tendrá una connotación reprochable y antijuridica, cuando con la operación se restrinja indebidamente la competencia dentro del mercado. Artículo 1 de la Ley 155 de 1959 y artículo 46 del Decreto 2153 de 1992.

Para evitar la configuración de un trust como una práctica restrictiva, nuestra legislación consagra un control previo, en virtud del cual, las empresas que reúnan ciertos requisitos y se propongan llevar a efecto una operación de concentración empresarial, deberán informarle, en algunos casos, o informarle y obtener autorización en otros, a la Superintendencia de Industria y Comercio para poder llevarla a cabo. Artículo 9 de la Ley 1340 de 2009.

Al respecto manifiesta la Superintendencia de Industria y Comercio en Resolución 29937 de 2010, lo siguiente:

El objeto del control de las integraciones ex ante no consiste en prohibir o en desincentivar las operaciones de concentración entre empresas, muchas de las cuales aparecen necesarias para el refuerzo de las estructuras industriales, sino en impedir aquellas cuyos inconvenientes sobre la libre competencia derivados de la modificación de la estructura del mercado y la reducción del número de operadores independientes, excederían las ventajas económicas y sociales.

Se trata entonces, este control previo, de una intervención legítima del Estado en la libertad económica y empresarial, como garantía de protección y mantenimiento de un sistema competitivo de libre mercado.

Como bien señala la Corte Constitucional en sentencia C-228 de 2010:

El grado de intervención estatal en la economía bien puede mostrarse desde una perspectiva sancionatoria de las prácticas contrarias de la libre competencia económica, como también de la prevención de actuaciones que por su 
naturaleza y potencial grado de influencia en la facultad de concurrencia de los agentes que concurren al mercado, puedan afectar dicha libertad.

Dentro de las modalidades de concentraciones empresariales que eventualmente se pueden configurar como prácticas restrictivas a la libre competencia, tenemos:

La fusión: dentro de los diversos tipos de fusión tenemos a la fusión por creación, en virtud de la cual 2 o más sociedades se disuelven sin liquidarse para crear una nueva sociedad; la fusión por absorción, en virtud de la cual una o más sociedades se disuelven sin liquidarse para ser absorbidas por una sociedad que ya existe (artículo 172 del Código de Comercio); la fusión abreviada, que ocurre cuando una sociedad detenta más del $90 \%$ de una sociedad por acciones simplificada, aquella podrá absorberla, caso en el cual la reforma se podrá autorizar por los órganos administrativos de las sociedades intervinientes y no por sus máximos órganos sociales (artículo 33 de la Ley 1258 de 2008).

Todos estos tipos de fusión se constituyen en reformas estatutarias, en las cuales se debe de tener en cuenta que, cuando las sociedades intervinientes llenen los presupuestos en cuanto a ingresos o activos y porcentaje del mercado, exigidos por la Ley 1340 de 2009 y la Superintendencia de Industria y Comercio ${ }^{3}$, tendrán que ponerla en conocimiento o solicitar el permiso correspondiente a dicha entidad para poder llevarla a efecto.

A la escritura pública de fusión se le deberá insertar el permiso de la SIC correspondiente. Numeral 1 del artículo 177 del Código de Comercio.

La función económica de las fusiones en palabras de Hincapié (2020), consiste en que "a través de la fusión se da la transferencia en bloque de activos de una sociedad o de varias, a la sociedad absorbente o a la nueva que resulte de la fusión". (p. 378).

Escisión: la escisión es otro tipo de operación que admite diversos tipos; así por ejemplo, existe la escisión total por creación y por absorción, en virtud de la cual una sociedad se disuelve sin liquidarse para la creación de dos o más sociedades, o para transferir en bloque su patrimonio a dos o más sociedades que ya existen; y la escisión parcial por creación o por absorción, en virtud de la cual una sociedad transfiere parte de su patrimonio a crear una o más sociedades o a ser absorbido por una o más sociedades que ya existen. Artículo 3 de la Ley 222 de 1995.

Con todo, tratándose de control previo de concentraciones empresariales, este ocurre cuando se trata de escisiones totales o parciales por absorción, en cuanto que es en estas modalidades de escisión donde se puede llegar a presentar una concentración restrictiva de la libre competencia.

En similares términos afirma Ortega (2005): “Debe entenderse, y así lo ha señalado la SIC, que en la escisión por creación no hay necesidad de solicitarle autorización (concepto de no objeción), puesto que evidentemente el fenómeno jurídico que acontece es el contrario a la integración". (p. 67).

3. Cuando en conjunto o individualmente considerados, las empresas que se dediquen a la misma actividad económica o participen en la misma cadena de valor, hayan tenido durante el año fiscal anterior a la operación ingresos operacionales o activos totales superiores a los 60.000 salarios mínimos legales mensuales vigentes, y cuenten con el $20 \%$ o más del mercado relevante, tendrán que solicitar autorización a la Superintendencia de Industria y Comercio. Artículo 9 de la Ley 1340 de 2009 
El artículo 227 de la Ley 222 de 1995, señala con respecto a la escisión: “En los casos de escisión de sociedades y en todos aquellos que impliquen consolidación, o integración de empresas o patrimonios, deberá darse cumplimiento a las normas sobre promoción de la competencia y prácticas comerciales restrictivas".

Es así, como al igual a como ocurre con la fusión, en la escritura pública de escisión se debe también de insertar el permiso de la Superintendencia de Industria y Comercio, autorizando la operación, cuando se requiera este en virtud de activos o pasivos y porcentaje del mercado de las sociedades intervinientes en la escisión. Numeral 1 artículo 8 de la Ley 222 de 1995.

Adquisición de control: de conformidad con el numeral 4 del artículo 45 del Decreto 2153 de 1992, por control se entiende:

La posibilidad de influenciar directa o indirectamente la política empresarial, la iniciación o terminación de la actividad de la empresa, la variación de la actividad a la que se dedica la empresa o la disposición de los bienes o derechos esenciales para el desarrollo de la actividad de la empresa.

En estos términos, se habla de situación de control cuando estamos en presencia de grupos de subordinación; es decir, cuando el poder de decisión de una sociedad se encuentra sometido a la voluntad de otra u otras personas; de tal suerte, que las sociedades cuya voluntad se encuentra sometida se denomina subordinada (bien como filial o como subsidiaria, dependiendo de si la subordinación se ejerce de forma directa o indirecta por parte de su controlante, respectivamente), mientras que la persona que ejerce el control se denomina matriz. Artículo 260 del Código de Comercio, modificado por el artículo 26 de la Ley 222 de 1995.

El artículo 261 del Código de Comercio, modificado por el artículo 27 de la Ley 222 de 1995, consagra tres casos no taxativos donde se presume que hay grupo de subordinación, los cuales son: cuando se tiene más del 50\% en el capital de una sociedad bien sea de manera directa, o través o con el concurso de otras subordinadas de la matriz; cuando se tiene la mayoría decisoria dentro de la asamblea de accionistas o junta de socios de la subordinada, o se tiene el número de votos necesarios para elegir a la mayoría de los miembros de la junta directiva; y cuando se tiene por parte de la matriz una influencia dominante en la subordinada, en virtud de un negocio o acto jurídico celebrado con esta o con sus socios.

Es de anotar, que a los dos primeros casos de presunción de subordinación que consagra el artículo 261 del estatuto mercantil, se les considera como un control de carácter interno o jurídico, mientras que al último se le considera como un control externo o económico.

Cuando además del vínculo de subordinación entre la matriz y sus subordinadas, existe unidad de propósito y dirección, estaremos en presencia de un grupo empresarial. Artículo 28 de la Ley 222 de 1995.

Ahora bien, cuando se presenta un grupo de subordinación, o un grupo empresarial, se establece todo un régimen para su adecuado funcionamiento, entre ellos la obligación de la matriz de hacer constar esta situación de control en documento privado inscrito en el registro mercantil de cada una de las sociedades vinculadas; 
lo anterior, para fines de oponibilidad frente a terceros de la existencia del grupo de subordinación o empresarial. Artículo 30 de la Ley 222 de 1995.

Igualmente el Decreto 667 de 2018, modificatorio del Decreto Único Reglamentario 1074 de 2015, consagra que cuando se vaya a inscribir la constitución de una sociedad por acciones simplificada con accionista único persona natural, la cámara de comercio correspondiente le entregara a este un formato para que proceda a inscribirse igualmente como controlante de la sociedad; en caso de rehusarse a realizar dicha inscripción, deberá manifestar el accionista único, quien posee el ejercicio del control sobre la sociedad.

Empero, no siempre que hay una adquisición de control en los términos atrás esbozados, estamos en presencia de una práctica restrictiva a la libre competencia, sino que la autoridad de competencia hace el análisis del caso concreto para entrar a determinar si se configura o no la práctica anticompetitiva con la adquisición del control dentro del mercado relevante correspondiente.

Así, por ejemplo, menciona la Superintendencia de Industria y Comercio en Resolución 31404 de 2011, que: "La adquisición de mayoría accionaria en una empresa por parte de otra, no necesariamente implica la realización de una integración empresarial, así como tampoco el adquirir, una participación accionaria inferior al 50\% significa que no hay situación de control"

En línea con lo anterior, hoy en día, se pueden presentar situaciones de control no convencionales, que adicionalmente tengan la potencialidad de convertirse en prácticas restrictivas a la libre competencia, en detrimento de los demás intervinientes en el mercado.

En estos términos, tenemos por ejemplo a los contratos que implican transferencia de tecnología como la franquicia, las licencias de uso de patentes o de secretos industriales o empresariales, que pueden encajar dentro del control externo o económico de presunción de subordinación del numeral 3 del artículo 261 del Código de Comercio, o dentro de las hipótesis de posibilidad de ejercicio de control por parte de los franquiciantes o licenciantes, en los términos del numeral 4 del artículo 45 del Decreto 2153 de 1992.

En otras palabras, el trust como práctica anticompetitiva, se puede también presentar hoy en día, a través de figuras contractuales no tan cotidianas en la configuración de vínculos de control.

De otro lado, es de anotar, que las modalidades de concentración que pueden afectar la libre competencia, no se agotan en la fusión, la escisión o en las adquisiciones de control.

Al respecto, afirma la Superintendencia de Industria y Comercio, en su guía de análisis de integraciones empresariales, que:

Forma Jurídica de una Integración: Hace referencia a la modalidad o vehículo jurídico a través del cual se materializa un cambio en la situación de control de una o más empresas, líneas de negocio y/o activos. Puede ser, por ejemplo, una adquisición de acciones, compra de activos, fusión, escisión, creación de una empresa, alianzas empresariales, contratos de franquicia, entre otras. 
En este orden de ideas, se pueden presentar actualmente diversas formas sofisticadas de concentración empresarial como prácticas restrictivas a la libre competencia que de contera pueden producir daños particulares a los participantes dentro del mercado.

En este sentido tenemos a la enajenación global de activos, consagrada en el artículo 32 de la Ley 1258 de 2008, consistente en que una sociedad por acciones simplificada se proponga enajenar activos y pasivos que representen el $50 \%$ o más de su patrimonio líquido al momento de la enajenación.

Dicha operación eventualmente puede afectar la libre competencia en el mercado, con el agravante que a diferencia de lo que ocurre con la fusión o escisión societarias, su procedimiento es mucho más expedito y fácil para la realización de concentraciones empresariales, entre otras, porque:

- A diferencia de la fusión no requiere para su perfeccionamiento de los cuórum y mayorías propias de una reforma estatutaria, máxime cuando en las sociedades por acciones simplificadas, no se requiere del requisito de la pluralidad para la configuración del cuórum deliberatorio.

- No se requiere de la solemnidad de la escritura pública, salvo que dentro de los activos haya bienes sujetos a registro, de ahí que cuando se trate de una enajenación global que recaiga únicamente sobre activos intangibles como bienes pertenecientes a la propiedad intelectual, esta se realice a través de documento privado.

- A diferencia de lo que ocurre con la fusión o con la escisión, al documento privado de enajenación global de activos, no se le requiere insertar el permiso de la Superintendencia de Industria y Comercio sobre prácticas restrictivas a la libre competencia, para proceder a su inscripción en el registro mercantil.

- A diferencia igualmente de lo que ocurre con la fusión o la escisión, los acreedores en la enajenación global, no tienen la posibilidad de ejercer la acción de oposición judicial, que eventualmente puede suspender el proceso de fusión o de escisión.

En oficio 220-097727 la Superintendencia de Sociedades, refiriéndose a la enajenación global de activos mencionó:

(...) este esquema no contempla ningún trámite de oposición por parte de los acreedores de la compañía, no establece responsabilidades solidarias entre la sociedad enajenante y el adquirente de lo vendido, ni requiere autorización de esta Entidad.

Así mismo, frente a la figura de la enajenación global de activos, manifiestan Rueda y Varón (2020): “...consideramos que esta estructura tiene grandes virtudes como es asegurar la celeridad de las transacciones mercantiles sin exigir un exceso de formalismos que en no pocas operaciones desincentivan el uso de las estructuras tradicionales..." (p. 123)

Otra figura que facilita la posibilidad de una concentración empresarial anticompetitiva, es el joint venture, entendido este como un contrato de colaboración empresarial de índole asociativo, del cual no surge una persona jurídica independiente de sus celebrantes, y en virtud del cual, varias personas físicas o jurídicas hacen unos aportes de industrias, de know how, de experiencia, de tecnología, de dinero, 
de bienes, etc., con el fin de llevar a cabo una empresa en común, generalmente un proyecto específico, con miras a repartirse las utilidades que genere su explotación.

Los contratos de joint venture son de carácter consensual, por lo que no están sujetos a ningún tipo de formalidad para su constitución, y aunque en principio tienen una duración determinada por el proyecto específico a desarrollar, esto no obsta para que eventualmente puedan restringir la competencia dentro de un mercado.

Con relación a los joint ventures manifiestan Barrera, Gutiérrez y Miranda (2014):

Tales actos jurídicos podrían llegar a constituirse en una forma de concentración empresarial. En efecto, una de las zonas grises es la que tiene que ver con la distinción entre una concentración y un acuerdo de colaboración empresarial. No todo acuerdo entre competidores, como un joint venture, tiene un efecto de concentración empresarial. (p. 175).

Así mismo, contratos de fiducia mercantil o de cuentas en participación, pueden tener la potencialidad de convertirse en un trust, de tal suerte que, en resumen, hoy en día, son muchas las figuras complejas y sofisticadas que se pueden estructurar, en las que eventualmente se puedan configurar concentraciones anticompetitivas en perjuicio no solamente del mercado en general, sino también de los intereses particulares de sus intervinientes.

Cabe anotar, por último, que, en materia de concentraciones empresariales, el artículo 12 de la Ley 1340 de 2009, consagra la denominada excepción de eficiencia, de acuerdo con la cual la Superintendencia de Industria y Comercio, no objetará una integración empresarial, si los interesados en la operación demuestran que sus beneficios para los consumidores exceden el impacto negativo que tendrá sobre la competencia.

Ahora bien, dicha excepción de eficiencia no es un impedimento para que los demás competidores que vean afectados sus intereses patrimoniales con la concentración proyectada, pueden acudir a las vías judiciales para que les sean indemnizados sus perjuicios.

\section{Régimen de Responsabilidad Civil en Materia de Prácticas Anticompetitivas}

Partiendo de las palabras de Alfonso Miranda Londoño, quien afirma que:

En Colombia no se ha avanzado aún en el tema de la indemnización de los perjuicios ocasionados por las prácticas restrictivas a la libre competencia, para lo cual los afectados cuentan con algunas opciones judiciales que no son especializadas y no han sido utilizadas hasta ahora de manera importante, por lo que se considera que esta es un área de desarrollo futuro para nuestro derecho de la competencia. (Instrumentos para la aplicación efectiva del derecho de la competencia en Colombia CEDEC).

Es que se hace necesario, plantear la estructuración de un régimen de responsabilidad especial en materia de daños ocasionados, con ocasión del ejercicio de prácticas anticompetitivas. 
En este orden de ideas, se pueden esgrimir como razones que exigen la estructuración de dicho régimen especial a las siguientes:

- El derecho de la competencia comprende lo que tiene que ver con el control de las prácticas restrictivas a la libre competencia, por un lado, y el control de los actos constitutivos de competencia desleal, por el otro; sin embargo, esta última a diferencia de las prácticas restrictivas, goza de un régimen de responsabilidad especial, tratándose de los daños que el acto desleal pueda ocasionar o tenga la potencialidad de generar.

Es así como en materia de competencia desleal, la Ley 256 de 1996, consagra no solamente, la acción judicial denominada declarativa o de condena, para que el afectado con el acto pueda perseguir la indemnización de los perjuicios que se le hayan ocasionado, sino que también, cuenta con una acción judicial denominada preventiva o de prohibición, para que se le ordene al posible infractor que se abstenga de llevar a cabo el acto desleal; es decir, en materia de competencia desleal, existen acciones tendientes a evitar que el acto de competencia desleal se perfeccione o que habiéndose perfeccionado no alcance a generar un daño.

Adicionalmente a ello, la Ley 256 de 1996, en concordancia con el Código General del Proceso, Ley 1564 de 2012, establece claramente los aspectos procesales que rigen el ejercicio de dichas acciones judiciales especiales en materia de competencia desleal; así por ejemplo, consagra quiénes son los legitimados por activa y por pasiva para su ejercicio; el trámite a seguir por dichas acciones que es el procedimiento verbal según su cuantía; el término de prescripción de las acciones; la posibilidad de adelantarse estas acciones judiciales a prevención ante los jueces civiles del circuito o ante la Superintendencia de Industria y Comercio, la cual es competente para conocerlas en ejercicio de funciones jurisdiccionales- articulo 24 Ley 1564 de 2012; la posibilidad de efectuar diligencias preliminares de comprobación, etc.

Con relación al régimen de responsabilidad especial en materia de competencia desleal, afirma Velásquez (2008):

Como novedad, la ley establece una responsabilidad objetiva, según la cual, para la configuración del acto de competencia desleal basta la infracción externa de la norma que la prohíbe más la presencia de un daño o amenaza, eliminando la consideración de todo elemente intencional o culposo. Además, tampoco exige la configuración del daño, pues dice que basta con la amenaza del mismo. (p. 239).

Adiciónese a lo anterior, que la Ley 256 de 1996, no se restringe únicamente su aplicación a los comerciantes competidores entre sí, sino que también es aplicable a todos los participantes dentro del mercado, tengan o no una relación de competencia.

Al respecto el artículo 3 de la Ley 256 de 1996, consagra que:

Esta ley se le aplicará tanto a los comerciantes como a cualesquiera otros participantes en el mercado. 
La aplicación de la ley no podrá supeditarse a la existencia de una relación de competencia entre el sujeto activo y el sujeto pasivo en el acto de competencia desleal.

En palabras de De la Cruz (2014)

La innecesaria existencia del requerimiento de la relación de competencia como condición para el ejercicio de acciones se debe a la evolución de la disciplina hacia el modelo social de la conducta que protege los intereses de todos en el mercado a través, no sólo de la tipificación de nuevos comportamientos o la consagración de cláusulas generales generosas en su contenido, sino también ampliando la legitimación para que los titulares de los intereses protegidos puedan defenderlos. (p. 35).

En comparación entonces con lo anterior, se itera, el régimen de prácticas restrictivas a la libre competencia, carece de un régimen especial de responsabilidad civil; como, por el contrario, si posee el tópico de la competencia desleal, lo que no se compadece con dos componentes del derecho de la competencia, cuya teleología común es el mantenimiento dentro del mercado de un sistema competitivo libre y transparente.

Como bien lo expresa Ortiz (2013) refiriéndose a estos dos sistemas pertenecientes al derecho de la competencia:

Desde sus orígenes y a lo largo de su desarrollo, los ordenamientos reguladores de la institución de la competencia económica, es decir, las normas que prescriben los comportamientos desleales y aquellas que garantizan la competencia entre competidores (normas antitrust) se han entrecruzado, enfrentado y complementado (...). El debate sobre la unidad del derecho de la competencia no es entonces un punto nuevo, pero es desde luego un asunto que sigue ocupando la atención de la doctrina y la jurisprudencia, y que aún no tiene una respuesta definitiva... (p. 646 y 647).

En este contexto, se puede afirmar que ambos regímenes pertenecientes al derecho de la competencia, tienen como finalidad la protección tanto de los intereses privados de los demás participantes en el mercado, como la salvaguarda de un interés público, como lo es el mantenimiento del orden público económico en un mercado leal y libremente concurrencial.

Así, frente a los intereses protegidos en materia de competencia desleal, menciona Medina (2008):

Como ordenamiento dirigido no solo a resolver los conflictos entre los competidores, sino además como instrumento de orden y control de las conductas en el mercado, esta ley no solo protege los intereses privados de los competidores sino también los colectivos de los consumidores y el interés público del Estado, que debe velar por la preservación de un sistema económico de competencia adecuado. (p. 362). 
Y por su parte, Ortiz (2013), refiriéndose a los intereses involucrados en las prácticas anticompetitivas, afirma que: "El ordenamiento antitrust, por su parte, despliega todos sus efectos de protección tanto del interés público como de los intereses privados cuando la afectación a la competencia tiene carácter sensible". (p. 640).

- Las prácticas restrictivas a la competencia, de por si, son un tema sumamente especializado, y hoy lo es aún más con los avances tecnológicos, la inteligencia artificial y el manejo de la propiedad intelectual, tal como lo mencionábamos en epígrafes anteriores; de ahí que los conflictos que se presenten con ocasión de los daños que se produzcan por la realización de dichas conductas, deben de ser del resorte de organismos técnicos, que tenga la capacidad y los conocimientos para entrar a determinar la existencia de la conducta anticompetitiva y el daño ocasionado, y no como actualmente sucede que dichas controversias son de competencia de los jueces civiles, los cuales a todas luces carecen de la experticia en este tipo de asuntos.

De ahí que al igual a lo que ocurre en materia de competencia desleal, donde a la Superintendencia de Industria y Comercio se le concedieron en virtud del artículo 24 de la Ley 1564 de 2012, facultades jurisdiccionales para conocer de estas conductas, también a este organismo técnico se le deberían de atribuir facultades jurisdiccionales para conocer de las prácticas restrictivas a la libre competencia.

Lo anterior resulta mucho más coherente con un sistema de protección verdaderamente comprensivo del sistema competitivo y del libre mercado, y de contera a un desarrollo de los postulados constitucionales de garantía a la libertad económica e intervencionismo estatal para la protección efectiva de la competencia.

- Dado que por los daños individuales que se le causen a un participante dentro del mercado, con ocasión de la realización de una práctica restrictiva a la libre competencia, no existe un régimen especial de responsabilidad, el afectado tendrá que acudir al régimen general de responsabilidad civil extracontractual contemplado en el artículo 2341 y siguientes del Código Civil.

Por lo tanto, para establecer entonces la responsabilidad civil y lograr la indemnización correspondiente, el damnificado tendrá que probar la configuración de la conducta anticompetitiva, el daño padecido, el nexo de causalidad entre la conducta y el daño ocasionado, y un factor de imputación subjetivo, esto es, que el agente dañador actuó con dolo o culpa en la realización de la práctica anticoncurrencial.

Lo anterior, por cuanto en Colombia, el régimen general de responsabilidad civil consagrado en nuestro sistema civil, es de carácter subjetivo con culpa probada; es decir, para poder endilgarle responsabilidad al agente causante del daño, a parte de la demostración de los elementos propios de toda responsabilidad civil, esto es la conducta, el daño y la relación de causalidad, hay igualmente que demostrar un factor subjetivo de imputación, esto es, que la conducta se desplegó a título de dolo o culpa. 
Al respecto la Corte Suprema de Justicia en sentencia del 30 de septiembre de 2016 , asevera:

Los requisitos que la ley exige para que el perjuicio que sufre una persona pase a ser responsabilidad de otra son: la presencia de un daño jurídicamente relevante, que éste sea normativamente atribuible al agente a quien se demanda la reparación; y que la conducta generadora del daño sea jurídicamente reprochable (en los casos de responsabilidad común por los delitos y las culpas).

En estos términos, igualmente se pronuncia Velandia (2011):

Otra cosa ocurre cuando se trata de una pretensión basada en la afectación a la competitividad, es decir que el comportamiento anticoncurrencial cause daño. En ese sentido, será necesario adelantar una imputación con ocasión del desmedro patrimonial de una empresa. Para ello cobra vigor el elemento culposo o doloso. (p. 362).

Ahora bien, en aras de morigerar la dificultad probatoria del elemento de imputación subjetivo para el agente damnificado, es que algunos manifiestan que, con la realización de la conducta anticompetitiva, lo que opera es una presunción de culpa en cabeza del agente dañador.

Así por ejemplo Carrillo (2016) argumenta:

Pues bien, en Colombia también es viable considerar que la violación de las normas de competencia conlleva la presunción del elemento culpa. Además, nuestro ordenamiento contempla la figura de la culpa presunta, en virtud de la cual se invierte la carga de la prueba y le corresponde al demandado demostrar que su actuar, además de ser licito, se enmarca en efecto dentro de la diligencia, cuidado y prudencia requeridos en el caso concreto. (p. 23).

De tal suerte que, bien sea una responsabilidad civil a título de culpa probada o a título de culpa presunta, el demandado tendrá como causal de exoneración de responsabilidad, no solamente la demostración de una causa extraña que destruya el nexo causal, sino que también podría exonerarse probando que actuó con la debida diligencia y cuidado.

Esta situación de la existencia de un factor de imputación subjetivo en materia de responsabilidad civil por daños producidos por prácticas anticoncurrenciales, no es coherente con el régimen de responsabilidad administrativo que para estas mismas conductas se encuentra establecido; pues en materia administrativa no se requiere el factor de atribución de la culpa o el dolo para endilgarle responsabilidad administrativa al agente infractor, como ya lo habíamos mencionado en el capítulo uno y dos de este escrito para el caso de la cartelización y el abuso de posición dominante, donde puede existir sanción por los efectos de dichas conductas independientemente de la intención de los agentes involucrados.

En este sentido, el régimen de responsabilidad más viable en materia de daños derivados de prácticas anticompetitivas, es el de un régimen de responsabilidad netamente objetivo, en virtud del cual el demandante, se encuentre dispensado de probar la culpa o el dolo del agente causante del daño, máxime por la dificultad de probar 
dichos elementos para el afectado dentro del ámbito del derecho de la competencia; y en esa misma dirección, la única forma de exonerarse de responsabilidad para el demandado, sería mediante la prueba de la existencia de una fuerza mayor o caso fortuito, de un hecho o culpa exclusiva de la víctima, o través de la prueba de un hecho o culpa exclusiva de un tercero.

Lo anterior, se relieva aún más si tenemos en cuenta que en materia de responsabilidad civil por daños ocasionados por actos constitutivos de competencia desleal, que es la otra gran rama constitutiva del derecho de la competencia, -complementaria de la prácticas anticompetitivas- la Ley 256 de 1996, establece es una responsabilidad objetiva, como menciona Carlos Alberto Velásquez Restrepo (2008):

Como novedad, la ley establece una responsabilidad objetiva, según la cual, para la configuración del acto de competencia desleal basta la infracción externa de la norma que la prohíbe más la presencia de un daño o amenaza, eliminando la consideración de todo elemente intencional o culposo. (p. 239).

En línea con lo anterior, es de tener en cuenta, que los regímenes de responsabilidad civil objetiva no se reducen únicamente a los casos de actividades riesgosas, pues en otras latitudes inclusive, se habla de responsabilidad objetiva cuando se trata de la vulneración de un derecho protegido, el cual, en materia de prácticas restrictivas, se constituiría en el derecho a la libre competencia económica, protegido no solamente de forma legal, sino también de manera constitucional.

En este sentido, indica Aramburo (2015):

Pero los criterios para la objetivación no solo atienden a la actividad desarrollada. El derecho anglosajón ha mostrado que la strict liability puede provenir (...) b) del derecho afectado (right-based strict liability), como ocurre con los torts de trespassing, en los que el ilícito consiste, simplemente, en no respetar el derecho protegido, sin que importe si hay culpa o no. (p. 188).

En este orden de ideas, podemos afirmar que, el criterio de atribución, tratándose de los daños derivados por la realización de una práctica restrictiva a la libre competencia, sería eminentemente objetivo como podría ser la vulneración de un derecho constitucional y legalmente protegido, la equidad, la justicia, la solidaridad y el no abuso del derecho.

Lo anterior no implica que la institución de la responsabilidad haya sido deformada por no requerir el elemento culpa en sus facetas de culpa en sentido estricto o dolo, por cuanto los elementos estructurantes de la misma siguen permaneciendo incólumes, como lo son: el daño, el hecho generador, el nexo de causalidad entre el hecho y el daño, y un factor de atribución, que simplemente, tratándose de la responsabilidad objetiva no es que desaparezca el factor de atribución como tal, sino que esta ya no será la culpa, sino que será el abuso del derecho, la solidaridad, la equidad, la justicia, el riesgo creado, etc. (Beltrán, 2016, p. 99).

Como diría igualmente López (2009) citando a Díaz Pairó: “...en el derecho moderno el sistema continúa siendo el tradicional de la responsabilidad subjetiva, aunque a título excepcional se hayan consagrado, cuando así lo han aconsejado razones de justicia, equidad o conveniencia, casos de responsabilidad objetiva". (p. 464 y 465). 
De otro lado, además de los beneficios jurídicos de una realización efectiva de la justicia material, un régimen de responsabilidad fundamentado en un factor de imputación objetivo, apareja igualmente una serie de beneficios de orden económico, pues funciona como un mecanismo idóneo para que los agentes intervinientes en el mercado, tengan incentivos para tomar las medidas necesarias para evitar incurrir en prácticas anticompetitivas y prevenir así los daños derivados de las mismas.

En palabras de Papayannis (2016):

La responsabilidad objetiva (...) brinda los incentivos correctos para que el agente dañador se comporte de manera eficiente. Como asumirá el coste total de su actividad, siempre le será conveniente tomar aquellas medidas, observables o no, que minimicen la indemnización que tendrá que pagar a las víctimas. (p. 51).

Desde este ángulo entonces, podemos considerar que el mecanismo óptimo para una adecuada asignación de los riesgos y de las pérdidas en un sistema de libre mercado, donde se pueden presentar conductas tendientes a limitar o inhibir la competencia con prácticas que, en todo caso, poseen una gran probabilidad y potencialidad de causar daños patrimoniales a los demás participantes en el mercado, es la configuración de un régimen objetivo de responsabilidad civil por daños ocasionados por conductas anticompetitivas, el cual facilita la declaración de responsabilidad del agente causante del daño, incentiva a tomar las medidas óptimas para evitar incurrir en las prácticas anticompetitivas, y de contera, ayuda a salvaguardar indirectamente el orden público económico de libre y leal competencia en el mercado.

En este sentido manifiesta Londoño (2020):

De esta forma, a través de instrumentos de derecho privado no solo se protegen los derechos subjetivos de personas que resultan afectadas por conductas antijuridicas de los encargados de la dirección de una empresa, sino también de forma indirecta el interés general que existe en que la empresa, que es fuente de creación de riqueza, bienestar, empleo y recursos tributarios, sea dirigida y administrada correctamente. En consecuencia, la responsabilidad civil constituye un importante instrumento de gobierno corporativo. (p. 194).

Y por su parte Viney (2010) aduce que:

La responsabilidad civil juega igualmente un papel preventivo real cuando sanciona los atentados a los derechos de la personalidad o a algunos intereses colectivos, profesionales o no materiales o morales, de los cuales algunos asociados toman hoy cada vez más eficazmente la defensa. (p. 91).

Adicionalmente, otro de los beneficios económicos que plantea la existencia de una responsabilidad objetiva, tiene que ver con el hecho de incentivarse el mercado de seguros, en la medida en que al constituirse estos, en mecanismos idóneos para dispersar el costo de los daños producidos, los agentes que participan en el mercado acudirán a la toma de seguros que amparen su eventual responsabilidad civil.

Ahora bien, en contraste con un sistema de responsabilidad civil subjetivo, que disminuye la cantidad de demandas judiciales debido a la dificultad para demostrar el factor de imputación culpa, es claro que, es más eficiente desde un punto de vista 
económico un sistema de responsabilidad objetivo, puesto que a pesar de aumentar el número de demandas por la relativa facilidad de establecer la responsabilidad del demandado, esta misma situación genera un incentivo para que se llegue a más conciliaciones entre los agentes involucrados en el litigio, lo que ahorra costos de tramitar todo un proceso judicial hasta su culminación, y adicionalmente a ello, las transacciones disminuyen los costos de la indemnización a pagar a la víctima.

Por otro lado, en cuanto al tema del daño derivado de conductas anticoncurrenciales, se ha considerado que este es un elemento de difícil determinación, no solamente en cuanto a su existencia sino también en cuanto a su cuantía.

Frente a dichas dificultades Polanco (2017), manifiesta que:

Dado que en Colombia no existen directrices, guías o parámetros para demostrar esta afectación, su comprobación resulta de difícil realización. Es más, esto ha resultado incluso complicado para la misma Autoridad de Competencia, quien no en muchas oportunidades ha logrado probar los efectos de las conductas restrictivas en el mercado, y en los casos en los que ha demostrado los efectos de la conducta no ha logrado calcular el monto de los daños (...)

El cálculo de los daños puede resultar difícil en la medida en que es necesario comparar la posición de bienestar de un consumidor o una empresa en presencia y ausencia de una infracción...

Con ocasión entonces de esta problemática que se plantea en cuanto a la dificultad existente, no solamente para la demostración del daño, sino también de su cuantía, es que, para estas situaciones, podrían adaptarse los criterios que para la determinación del monto del daño existen en materia de propiedad industrial, de tal forma que el participante en el mercado, cuyos intereses patrimoniales se hayan visto afectados con la conducta restrictiva, se pueda basar en ellos para establecer su indemnización.

Los citados parámetros se encuentran en el artículo 243 de la Decisión 486 de 2000, de la Comunidad Andina de Naciones, y hacen referencia a que para calcular la indemnización de daños y perjuicios en materia de violación a la propiedad industrial se deben de tener en cuenta, entre otros:

a. El daño emergente y el lucro cesante sufrido por el titular del derecho como consecuencia de la infracción

b. El monto de los beneficios obtenidos por el infractor como resultado de los actos de infracción

Con todo, dichos criterios pueden funcionar como directrices a tener en cuenta por el perjudicado para tasar el monto de sus perjuicios, mas no responden a la dificultad probatoria de los mismos en el ámbito de las prácticas restrictivas, de ahí, que adicionalmente, se proponga para el evento en que sea sumamente complejo para el damnificado su cuantificación, que exista una valoración legal de los mismos, lo cual se acompasa con una responsabilidad de tipo objetivo.

La valoración legal del daño según Medina (2015): “Obedece a tarifas preestablecidas por la ley, y corresponde casi siempre a situaciones de responsabilidad objetiva" (p. 11). 
Dichas valoraciones legales ya han sido aplicadas en el derecho anglosajón en los ámbitos propios de la propiedad intelectual, con el nombre de statutory damages, debido precisamente a la dificultad para establecer la cuantía indemnizable.

En tal sentido, manifiesta Plata (2010):

Muchas veces probar los perjuicios del demandante o las ganancias del demandado no es una tarea fácil, o tal vez son sumas que no satisfacen o resarcen de manera total y completa los perjuicios sufridos por el titular de los derechos de copyright.

Es por esta razón que la ley trae unos perjuicios prestablecidos, a los cuales el demandante puede acogerse en cualquier momento antes de que se dicte fallo. (p. 169).

Por otro lado, es de anotar que en materia de prácticas restrictivas a la libre competencia, no existe la posibilidad para el posible afectado con la conducta, de ejercer algún tipo de acción judicial individual para que se le ordene a la empresa y/o empresas involucradas, abstenerse de llevar adelante el acto anticompetitivo, para de esa manera evitar así la producción del daño personal que pueda padecer aquel; a diferencia de lo que sí ocurre tratándose de los actos constitutivos de competencia desleal, donde quien se pueda ver afectado en sus intereses económicos con la deslealtad de la práctica, puede ejercer la acción preventiva o de prohibición del numeral 2 del artículo 20 de la Ley 256 de 1996, sin que aún se le haya ocasionado algún tipo de daño, o inclusive sin que la conducta desleal se haya efectivamente perfeccionado.

Por esta razón, se le debería de conceder una acción judicial de carácter individual al posible afectado con la conducta anticoncurrencial, antes de que esta se perfeccione, o habiéndose consolidado, antes de que cause de manera efectiva un daño.

A pesar de ello, se podría aducir que al estar consagrado en nuestra Constitución el derecho a la libre competencia económica, como un derecho de carácter colectivo, el posible afectado con la práctica restrictiva podría iniciar una acción popular, la cual tiene una función precisamente preventiva para evitar la realización del daño. Articulo 88 Constitución Política de 1991 y Ley 472 de 1998.

Al respecto señala el inciso 2 del artículo 2 de la Ley 472 de 1998: "Las acciones populares se ejercen para evitar el daño contingente, hacer cesar el peligro, la amenaza, la vulneración o agravio sobre los derechos e intereses colectivos, o restituir las cosas a su estado anterior cuando fuere posible".

Sin embargo; la acción popular se constituye en una acción propia de protección de un interés colectivo, es decir, que se radica en un grupo amplio de personas y que por ende no está establecida para la protección de daños individuales o subjetivos, lo que excluye por tanto su uso cuando se trata de la protección de intereses patrimoniales de un solo sujeto como posible único afectado con una conducta anticoncurrencial.

Define la Corte Constitucional en sentencia T-097 de 2014, a los derechos colectivos como: "el interés que se encuentra en cabeza de un grupo de individuos, lo que excluye motivaciones meramente subjetivas o particulares". 
En síntesis, por todas estas consideraciones, se plantea la viabilidad de estructurar un sistema particular de responsabilidad civil por los daños derivados de las prácticas anticompetitivas, que responda adecuadamente a los perjuicios que eventualmente puedan padecer los participantes dentro del mercado.

\section{Conclusiones}

Existen puntos de encuentro y complementariedad entre las normas de protección a la libre competencia y las normas de protección a la competencia desleal, como componentes ambas normativas del derecho de la competencia, en la medida en que tanto en unas como en otras se vela por la protección general del mercado y el orden público económico, así como también por la salvaguarda de los intereses privados de los intervinientes dentro del mismo.

Existe todo un régimen normativo particular en materia de responsabilidad civil por los daños ocasionados por actos constitutivos de competencia desleal en la Ley 256 de 1996, régimen del cual carecen los afectados con las prácticas restrictivas a la libre competencia, teniendo que acudir estos, al régimen general de responsabilidad civil con culpa probada contenido en el Código Civil; situación que no es coherente con un derecho de la competencia que debe propender por la protección adecuada y comprensiva de los agentes intervinientes en el mercado, que se pueden ver afectados tanto por conductas desleales como anticompetitivas.

Debido a los avances tecnológicos que hoy en día existen en materia de manejo de propiedad intelectual, softwares, inteligencia artificial, big data, entre otros, y a las nuevas formas de negociación contractual, existe la posibilidad que se realicen prácticas anticompetitivas mucho más sofisticadas y complejas, con una alta potencialidad de causar daños a los agentes intervinientes dentro del mercado; de ahí que se hace indispensable un régimen particular de responsabilidad civil que responda mucho más adecuadamente a los daños que como consecuencia de estas conductas se lleguen a producir.

Dentro de las características propias de un régimen de responsabilidad particular por los daños derivados de prácticas restrictivas a la libre competencia, que responda a las nuevas formas en que estas se pueden llevar a cabo, está el que se constituya en una responsabilidad objetiva, dada la dificultad para demostrar la culpabilidad de los agentes involucrados en la conducta; el que se establezca la posibilidad de acudir a una valoración legal del daño, en los eventos en que también sea sumamente complejo determinar la cuantía de los mismos; el que exista una acción judicial individual tendiente a evitar que se perfeccione el daño con la conducta anticompetitiva; y que sea competente para conocer de este régimen de responsabilidad una autoridad técnica como la Superintendencia de Industria y Comercio, en ejercicio de funciones jurisdiccionales.

Bajo un análisis económico, una responsabilidad civil objetiva en materia de daños derivados por prácticas comerciales restrictivas, genera incentivos para que los intervinientes en el mercado se abstengan de realizar conductas anticompetitivas, y para que por el contrario, tomen las medidas necesarias para evitar incurrir en las mismas, salvaguardando de contera y de forma indirecta el orden público económico de libre y leal competencia en el mercado. 


\section{Referencias}

Aramburo, M. (2015). Modernizar la responsabilidad extracontractual. Un mapa de problemas. En Castro, M. (Coord.) Modernización de las obligaciones y los contratos. (pp. 153-212). Bogotá: Temis.

Barrera, N. y Gutierrez, J. y Miranda, A. (2014). El control de las concentraciones empresariales en Colombia. Bogotá: Ibañez.

Beltrán, G. (2016). La constitucionalización de la responsabilidad civil por actividades peligrosas en Colombia. Medellín: Universidad de Medellín.

Berdugo, J. y Palacio, R. (2011). Las asociaciones. Instrumento para la creación de empresas. Medellín: Universidad de Medellín.

Calderón, A. (2019). Cartel fácil: estudio comparado sobre los facilitadores de colusión en el derecho de la competencia en América del Sur. En Celis, J. (Ed.) Avances en derecho de la competencia. Cedec XVIII. (pp.31-63). Bogotá: Grupo Editorial Ibañez.

Carrillo, P. (2016). Responsabilidad civil derivada de prácticas anticompetitivas: estudio de sus presupuestos axiológicos. Revista derecho privado. Universidad de los Andes Vol: 56, [pp. 3-30].

Castro, M. (2016). Derecho comercial. Actos de comercio, empresas, comerciantes y empresarios. (Segunda Ed). Bogotá: Temis.

CEDEC (2020). Instrumentos para la aplicación efectiva del derecho de la competencia en Colombia. Recuperado de https://centrocedec.org/articulos/

Cobar, L. (2019). Los mercados digitales y los retos para el derecho de la competencia. En Celis, J. (Ed.) Avances en derecho de la competencia. Cedec XVIII. (pp.65-87). Bogotá: Grupo Editorial Ibañez.

Código Civil [Código]. (2019) 42 ed. Legis

Código de Comercio [Código]. (2019) 41 ed. Legis

Comisión de la Comunidad Andina. (2000). Régimen común sobre propiedad industrial. [Decisión 486]

Constitución Política de Colombia. Gaceta Constitucional No. 116 de 20 de julio de 1991.

Congreso de Colombia. (18 de enero de 1996). Ley por medio de la cual se dictan normas sobre competencia desleal. [Ley 256 de 1996] D0: 42.692

Congreso de Colombia. (24 de julio de 2009). Ley por medio de la cual se dictan normas en materia de protección de la competencia. [Ley 1340 de 2009] D0: 47.420

Congreso de Colombia. (22 de enero de 1960). Ley por medio de la cual se dictan disposiciones sobre prácticas comerciales restrictivas. [Ley 155 de 1959] D0: 30.138

Congreso de Colombia. (20 de diciembre de 1995). Ley por la cual se modifica el libro II del Código de Comercio, se expide un nuevo régimen de procesos concursales y dictan otras disposiciones. [Ley 222 de 1995] DO: 42.156.

Congreso de Colombia. (12 de julio de 2012). Por medio de la cual se expide el Código General del Proceso y se dictan otras disposiciones. [Ley 1564 de 2012] D0: 48.489

Congreso de Colombia. (5 de diciembre de 2008). Ley por medio de la cual se crea la sociedad por acciones simplificada. [Ley 1258 de 2008] DO: 47.194

Congreso de Colombia. (6 de agosto de 1998). Ley por medio de la cual se desarrolla el artículo 88 de la Constitución Política de Colombia en relación con el ejercicio de las acciones populares y de grupo y se dictan otras disposiciones. [Ley $472 \mathrm{de}$ 1998] DO 43.357

Cortázar, J. (2011). Curso de derecho de la competencia. (Antimonopolios). Bogotá: Temis.

Corte Constitucional. (13 de junio de 2001) Sentencia C-616 [MP Rodrigo Escobar Gil]

Corte Constitucional. (14 de agosto de 1997) Sentencia T-375 [MP Eduardo Cifuentes Muñoz]

Corte Constitucional. (2 de agosto de 2001) Sentencia C-815 [MP Rodrigo Escobar Gil] 
Corte Constitucional. (24 de marzo de 2010) Sentencia C-228 [MP Luis Ernesto Vargas Silva]

Corte Constitucional. (20 de febrero de 204) Sentencia T-097 [MP Luis Ernesto Vargas Silva]

Corte Suprema de Justicia, Sala de Casación Civil. (30 de septiembre de 2016) Sentencia SC 13925. [Ariel Salazar Ramírez]

De la Cruz, D. (2014). La competencia desleal en Colombia, un estudio sustantivo de la ley. Bogotá: Universidad Externado de Colombia.

Ibarra, G. (2019). Columnas sobre derecho de la competencia. En Celis, J. (Ed.) Avances en derecho de la competencia. Cedec XVIII. (pp.161-185). Bogotá: Grupo Editorial Ibañez.

Hincapié, M.L. (2020). Formas asociativas: el derecho de las asociaciones. Medellín: Sello editorial Universidad de Medellín.

Jiménez, F. (2019). Derecho de la competencia. Bogotá: Grupo Editorial Legis.

León, I. y Varela, E. (2010). El abuso de la propiedad intelectual como fuente para la aplicación de la teoría del levantamiento del velo corporativo. En Universidad del Rosario (Ed.) Levantamiento del velo corporativo. Panorama y perspectivas. El caso colombiano. (pp. 353-368). Bogotá: Universidad del Rosario.

Londoño, M. (2020). Aspectos relevantes de la responsabilidad civil de los accionistas de la S.A.S. En Mesa, L. (Coord.) Diez años de las S.A.S. Análisis y perspectivas desde una visión académica. (pp. 191-216). Bogotá: Ibañez.

López, M. (2009). Elementos de la responsabilidad civil. Bogotá: Universidad Javeriana. Medina, J. (2008). Derecho comercial. Parte general. (Cuarta Ed). Bogotá: Temis.

Medina, J. (2015). Responsabilidad comercial. De las sociedades y sus vinculados. Bogotá: Temis.

Miranda, A. (10 de junio de 2019). La posición de dominio en los mercados de las tics. El tiempo. Recuperado https://www.eltiempo.com/economia/sectores/la-posicionde-dominio-en-los-mercados-de-las-tics-373798

OCDE (2014). ficha informativa sobre los efectos macroeconómicos de la política de competencia. Recuperado de https://www.oecd.org/daf/competition/2014-competition-factsheet-print-es.pdf

Ortega, M. (2005). Fusión, escisión, y segregación. En Quiceno, E. (Ed.) Aspectos prácticos de las sociedades mercantiles. (pp. 57-74). Medellín: Dike.

Ortiz, I. (2013). Las normas de libre competencia y de competencia desleal: criterios históricos de separación y convergencia. En Sotomonte, S. (Dir.) Del derecho comercial al derecho del mercado. (pp. 581-652). Bogotá: Universidad Externado de Colombia.

Pacheco, E. (2020). Análisis económico de la protección al software. Hacia un nuevo modelo de protección. Bogotá: Ibañez.

Papayannis, D. (2016). El derecho privado como cuestión pública. Bogotá: Universidad Externado de Colombia.

Pineda, E. (2013). Abuso del derecho y de la posición dominante. En Quiceno, E. (Ed.) La distribución comercial en un mercado global. (pp. 75-95). Medellín: Dike.

Plata, L. (2010). Responsabilidad civil por infracciones al derecho de autor. Barranquilla: Ediciones Uninorte.

Polanco, C (2017). Las acciones de responsabilidad civil por prácticas restrictivas de la competencia y su incidencia en la decisión de restringir la misma en Colombia. Recuperado file:///C:/Users/PERSONAL/Desktop/ARTICULOS\%20PUBLICABLES/ Art\%C3\%ADculo\%20competencia\%20carolina\%20polanco.pdf

Presidencia de la Republica. (31 de diciembre de 1992). Decreto por el cual se reestructura la Superintendencia de Industria y Comercio y se dictan otras disposiciones. [Decreto 2153 de 1992] DO: 40.704. 
Presidencia de la República. (18 de abril de 2018). Decreto por el cual se agrega una sección al capítulo 41 del título 2 de la parte 2 del libro 2 del Decreto único reglamentario del sector Comercio, Industria y Turismo, número 1074 de 2015. [Decreto 667 de 2018] DO: 50.568.

Presidencia de la Republica. (16 de julio de 2015). Decreto por el cual se reglamenta el artículo 14 de la Ley 1340 de 2009 y se modifica el capítulo 29 del Título 2 de la parte 2 del libro 2 del Decreto Único Reglamentario del Sector Comercio, Industria y Turismo, Decreto 1074 de 2015, sobre beneficios de las personas naturales y jurídicas que colaboren en la detección y represión de acuerdos restrictivos de la libre competencia. [Decreto 1523 de 2015] DO: 49.575.

Rengifo, E. (2004). Del abuso del derecho al abuso de la posición dominante. (segunda Ed). Bogotá: Universidad Externado de Colombia.

Rubio, J. (2007). Derecho de los mercados. Propiedad industrial, competencia, protección al consumidor. Bogotá: Grupo Editorial Legis.

Rueda, A. y Varón, J. (2020). La enajenación global de activos como una operación de organización societaria en las sociedades por acciones simplificadas. En Mesa, L. (Coord.) Diez años de las S.A.S. Análisis y perspectivas desde una visión académica. (pp. 101-123). Bogotá: Ibañez.

Superintendencia de Industria y Comercio. Resolución 26129 de 2015.

Superintendencia de Industria y Comercio. Resolución 3694 de 2013.

Superintendencia de Industria y Comercio. Resolución 29937 de 2010.

Superintendencia de Industria y Comercio. Resolución 31404 de 2011.

Superintendencia de Industria y Comercio. Cartilla sobre la aplicación de las normas de competencia frente a las asociaciones de empresas y asociaciones o colegios de profesionales. Recuperado de https://www.sic.gov.co/recursos user/documentos/CARTILLA GREMIOS.pdf

Superintendencia de industria y comercio. Guía de análisis de integraciones empresariales. Tramites de preevaluación 2018. Recuperado de https://www.sic. gov.co/sites/default/files/files/Proteccion Competencia/Integraciones Empresariales/2019/Gu\%C3\%ADa\%20Integraciones\%20Empresariales agosto16_2019\%20(1).pdf

Superintendencia de Industria y Comercio. Preguntas frecuentes régimen de protección de la competencia. Recuperado de https://www.sic.gov.co/sites/default/ files/files/Nuestra Entidad/Publicaciones/Preguntas frecuentes Regimen de Proteccion de la Competencia.pdf

Superintendencia de Sociedades. Oficio 220-097727 del 27 de junio de 2016.

Tobar, J. (2016). Deberes del comerciante frente a las normas del derecho de la competencia. En Cárdenas, J. Calderón, J. y López, Y. (Eds.) Derecho comercial. Cuestiones fundamentales. (pp. 343-364). Bogotá: Legis.

Velandia, M. (2011). Derecho de la competencia y del consumo. Competencia desleal; abuso de la posición de dominio; carteles restrictivos; actos restrictivos; integraciones económicas y protección al consumidor. (Segunda Ed). Bogotá: Universidad Externado de Colombia.

Velásquez, C. (2008). Instituciones de derecho comercial. Medellín: Señal Editora.

Velilla, M. (2013). Introducción al derecho económico y de los negocios. Las transformaciones aplicadas al derecho moderno. Bogotá: Grupo Editorial Gestión 2000

Viney, G. (2010). Tratado de derecho civil. Introducción a la responsabilidad. Bogotá: Universidad Externado de Colombia. 